\title{
Performance de associações de herbicidas em cana-de-açúcar (Saccharum officinarum)
}

\section{Performance of herbicides mixtures in sugar cane (Saccharum officinarum)}

\author{
Miriam Hiroko Inoue ${ }^{1}$, Anderson José Santin ${ }^{2}$, Rivanildo Dallacort ${ }^{1}$, Ana Cássia Silva Possamai ${ }^{3}$ \\ Diogo Carneiro de Santana ${ }^{3}$
}

\begin{abstract}
Resumo - A presente pesquisa teve como objetivo avaliar a seletividade e a eficácia de associações de herbicidas na cultura da cana-de-açúcar variedade RB 83-5486. Para tanto, foram instalados quatro ensaios de pesquisa, sendo dois localizados no município de Nova Londrina, PR, e dois em Marilena, PR. O delineamento experimental utilizado foi o de blocos casualizados, com nove tratamentos e quatro repetições. Em todos os ensaios, os tratamentos foram aplicados em pré-emergência da cana-de-açúcar e das plantas daninhas, a saber: T1 (tebuthiuron) + (hexazinone + diuron), T2 (clomazone + ametrina) + (clomazone), T3 (clomazone + ametrina), T4 (trifloxysulfuron sodium + ametrina), T5 (trifloxysulfuron sodium + ametrina) + (hexazinone + diuron), T6 (clomazone + ametrina) + (hexazinone + diuron), T7 (hexazinone + diuron) + (clomazone), além das testemunhas sem aplicação de herbicidas (T8 - capinada e T9 - sem capina). A maioria dos tratamentos causou leves sintomas de fitotoxicidade na cultura. No entanto, em todos os ensaios, foram observados que aos 100 dias após a aplicação (DAA) as plantas de cana-de-açúcar se recuperaram desses sintomas de fitotoxicidade. Em Nova Londrina, T1 e T7 foram os tratamentos que atingiram controle total de plantas daninhas até aos 100 DAA. Do mesmo modo, os tratamentos T5 e T6 se destacaram no controle das plantas daninhas em Marilena. Nas duas localidades, a biomassa seca da parte aérea da cultura obtida aos 150 DAA nas parcelas tratadas com os herbicidas, não apresentou diferenças significativas em relação à testemunha capinada. Já a interferência das plantas daninhas proporcionou reduções no desenvolvimento da cultura, que variam de $49,9 \%$ e 56,2\%, respectivamente para as áreas de Nova Londrina e Marilena.
\end{abstract}

Palavras-chave: Fitotoxicidade, manejo, plantas daninhas.

\begin{abstract}
The present work was aimed to evaluate the selectivity and efficiency of herbicides mixtures in sugar cane variety RB 83-5486. Four experiments were carried out in Nova Londrina (PR) and Marilena (PR). In each locality were developed two experiments. The experiments were conducted in randomized blocks, with nine treatments and four replications. In all experiments, the treatments were applied in pre-emergence: T1 (tebuthiuron) + (hexazinone + diuron), T2 (clomazone + ametrina) + (clomazone), $\mathrm{T} 3$ (clomazone + ametrina), T4 (trifloxysulfuron sodium + ametrina), T5 (trifloxysulfuron sodium + ametrina) + (hexazinone + diuron), T6 (clomazone + ametrina $+($ hexazinone + diuron $), \mathrm{T} 7$ (hexazinone + diuron $)+($ clomazone $)$, and two untreated

\footnotetext{
${ }^{1}$ Professor(a) do Departamento de Agronomia da Universidade do Estado de Mato Grosso (UNEMAT), Rodovia MT 358, Km 7, 78300-000, Tangará da Serra, MT. E-mail:<miriamhinoue@ hotmail.com>.

${ }^{2}$ Eng. Agro., Técnico da Syngenta do Brasil.

${ }^{3}$ Aluno(a) do curso de Agronomia da UNEMAT.
}

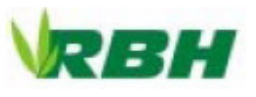


checks (T8 - weedy and T9 - weed-free). Most treatments caused phytotoxicity in the culture. However, in all experiments, the crop recovered from the phytotoxicity caused by chemical treatments at 100 days after the application. T1 and T7 (Nova Londrina) and T5 and T6 (Marilena) provided total control of weeds up to 100 DAA. In both localities, the biomass accumulation at 150 DAA of the herbicides indicated no significant differences, in comparison with the weed-free ckeck. The weed interference reduced sugar cane biomass from 49,9\% (Nova Londrina) to $56,2 \%$ (Marilena).

Key-words: Phytotoxicity, management, weeds.

\section{Introdução}

A cana-de-açúcar (Saccharum officinarum) é uma das culturas mais importantes para o Brasil, tem exercido uma função duplamente destacável. Por um lado, a produção açucareira fundamenta grande parte das divisas do país, que tem se apresentado como o maior exportador mundial de açúcar; Por outro, a produção de álcool constitui importante alternativa brasileira à substituição de determinados derivados do petróleo (Negrisoli, 2003). Portanto, essa cultura ocupa uma posição de destaque na agricultura nacional, principalmente após o incentivo ao desenvolvimento da bioconversão de energia, como alternativa para o fornecimento de combustível (Constantin et al., 2002).

De acordo com Barela \& Christoffoleti (2006), a cultura da cana-deaçúcar absorve grande quantidade de mão-deobra e insumos no seu ciclo de produção. Dentre esses produtos, a cana-de-açúcar é a segunda cultura em consumo de herbicidas no Brasil, atrás apenas da soja (IEA, 2008).

No Paraná, a cana-de-açúcar é um dos principais produtos agrícolas nas regiões Norte e Noroeste. Estima-se que o Estado produziu 52,9 milhões de toneladas de cana-de-açúcar na safra 2007/08, sendo destinada 48,3 milhões de toneladas para a fabricação de açúcar e álcool e o restante à fabricação de cachaça, na alimentação animal e em outras pequenas atividades produtivas (CONAB, 2008).
A interferência negativa exercida pelas plantas daninhas é, sem dúvida, um dos mais importantes fatores que determinam perdas à quantidade e a qualidade da cana-deaçúcar produzida, pois as mesmas competem pelos recursos limitantes do ambiente (água, luz e nutrientes), podem liberar substâncias alelopáticas e até hospedar pragas e patógenos comuns à cultura, além de interferirem no rendimento da cultura (Blanco et al., 1982). Lorenzi (1995) relatou que, dependendo da infestação, o controle das plantas daninhas pode chegar a até $30 \%$ do custo de produção em cana-soca e entre 15 e $25 \%$ em cana-planta. Portanto, um manejo adequado das plantas daninhas é essencial para se ter lucratividade nesse segmento agrícola.

O objetivo deste trabalho foi avaliar diferentes opções de associações de herbicidas aplicados em pré-emergência da cana-deaçúcar e das plantas daninhas no estado do Paraná, com o intuito de verificar a seletividade na cana-de-açúcar e a eficácia no controle das plantas daninhas, em duas localidades.

\section{Material e métodos}

A presente pesquisa constou de quatro ensaios conduzidos em áreas pertencentes a Usina COPAGRA (Cooperativa Agroindustrial do Noroeste Paranaense), sendo dois ensaios localizados no município de Nova Londrina, PR, e dois em Marilena, PR. As áreas experimentais selecionadas se caracterizam por solo de textura arenosa, conforme pode-se observar na Tabela 1. Em cada localidade 
foram conduzidos dois experimentos contendo os mesmos tratamentos; um visando avaliar a seletividade de associações de herbicidas na cana-de-açúcar e outro com o objetivo de verificar o controle de plantas daninhas dos mesmos tratamentos químicos. Para cada experimento foi utilizado o delineamento em blocos casualizados, com nove tratamentos e quatro repetições. As parcelas experimentais possuíam $9 \mathrm{~m}$ de largura por $10 \mathrm{~m}$ comprimento, sendo utilizado com área útil 72 $\mathrm{m}^{2}$

Os tratamentos constituíram-se de sete opções de associações de herbicidas, além das testemunhas sem aplicação de herbicidas (testemunhas capinada e sem capina), totalizando 9 tratamentos para cada experimento (Tabela 2). A testemunha capinada permaneceu isenta de plantas daninhas durante todo ciclo da cultura, por meio de capina manual. Nos experimentos de seletividade, todas as parcelas que receberam os tratamentos químicos também permaneceram livres de plantas daninhas durante todo o período de condução dos experimentos, por meio de capina manual. Por outro lado, não foi utilizado nenhum método de controle das plantas daninhas na testemunha sem capina.

Tabela 1. Características químicas e físicas dos solos presentes nas áreas em que os experimentos foram conduzidos.

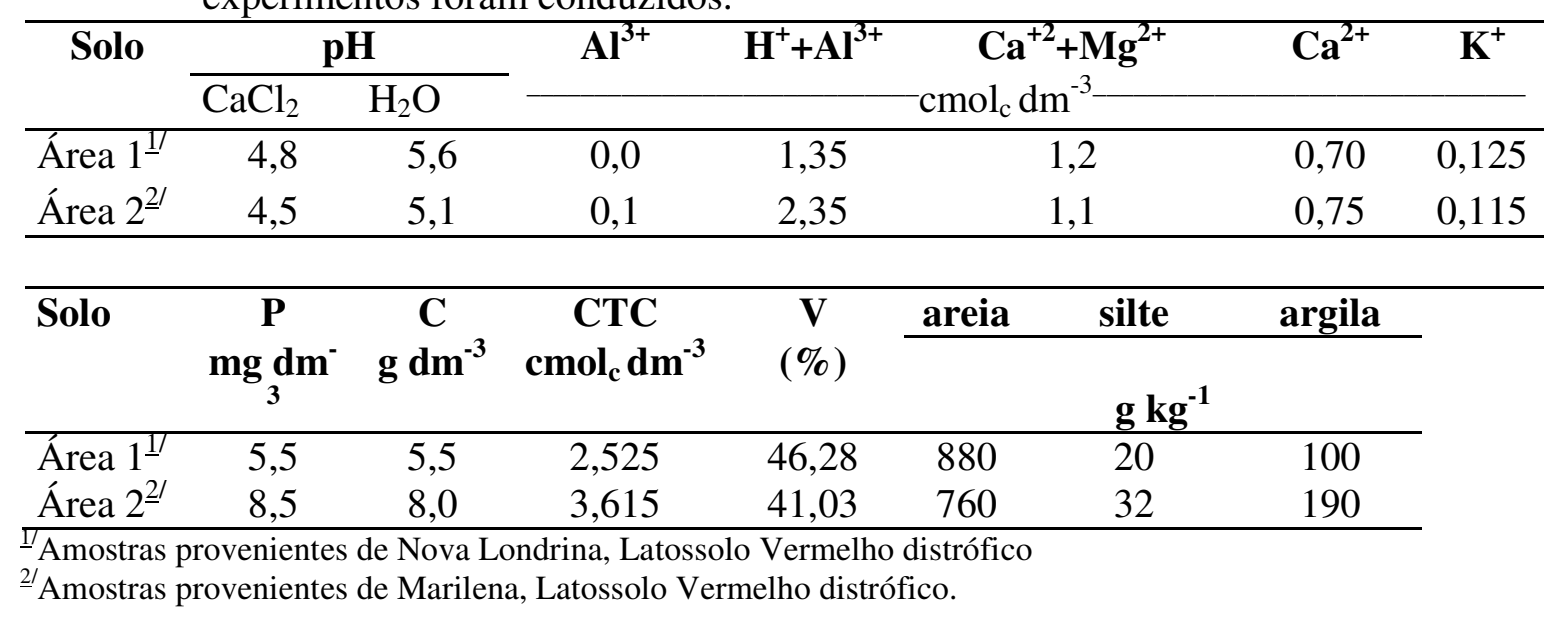

Em ambas as áreas experimentais, realizou-se adubação de plantio com $1.200 \mathrm{~kg}$ da formulação 08-30-20 (N, $\mathrm{P}_{2} \mathrm{O}_{5}$ e $\left.\mathrm{K}_{2} \mathrm{O}\right)$. A primeira área está situada no sítio Pôr do Sol em Nova Londrina, PR, onde o plantio foi no dia 24 de Maio de 2006. A segunda área está localizada na fazenda Boa Esperança no município de Marilena, PR (área 2) e o plantio foi realizado em 05 de Junho de 2006. Em todos os experimentos, utilizaram-se a variedade RB 83-5486, com densidade de 14 a 18 gemas por metro linear, com espaçamento de 1,40 $\mathrm{m}$ entre linhas. A aplicação dos tratamentos nas áreas de Marilena ocorreu em 28 de Maio de 2006, enquanto que nas áreas de Nova Londrina em 10 de Junho 2006, ambas em condição de pré-emergência da cana-deaçúcar e das plantas daninhas.

Todas as aplicações de herbicidas foram realizadas com um pulverizador costal de pressão constante à base de $\mathrm{CO}_{2}$, equipado com pontas tipo leque XR110.02, pressão de 2,0 kgf $\mathrm{cm}^{-2}$, proporcionando o equivalente a $200 \mathrm{~L} \mathrm{ha}^{-}$ 1 de calda. No momento da aplicação dos tratamentos em Nova Londrina a temperatura do ambiente era de $30^{\circ} \mathrm{C}$, umidade relativa do 
ar de $75 \%$, velocidade do vento próximo a $590 \%$, sem presença de ventos e o solo, e em $\mathrm{km} \mathrm{h}^{-1}$ e o solo estava seco, em virtude da falta relação a área 1 , se encontrava com maior de chuva na época da realização do trabalho. percentual de umidade em virtude da Em Marilena a temperatura estava em torno de precipitação $(19 \mathrm{~mm})$ que ocorreu na área dois $23^{\circ} \mathrm{C}$, umidade relativa do ar estava na faixa de dias antes da aplicação dos tratamentos.

Tabela 2. Tratamentos e doses dos herbicidas utilizados nos experimentos desenvolvidos em Nova Londrina/PR e Marilena/PR.

\begin{tabular}{lc}
\hline \multicolumn{1}{c}{ Tratamentos } & DOSES $\left(\mathbf{g}\right.$ i.a. ha $\left.{ }^{-1}\right)$ \\
\hline T1- (tebuthiuron) + (hexazinone + diuron) & $(650)+(171,6+608,4)$ \\
T2- (clomazone + ametrina) + (clomazone) & $(800+1200)+(500)$ \\
T3- (clomazone + ametrina) & $(1000+1500)$ \\
T4- (trifloxysulfuron sodium + ametrina) & $(40,7+1609,3)$ \\
T5-(trifloxysulfuron sodium + ametrina) + (hexazinone + & $(27,7+1097,2)+(171,6+$ \\
diuron) & $608,4)$ \\
T6- (clomazone + ametrina) + (hexazinone + diuron) & $(800+1200)+(132+468)$ \\
T7- (hexazinone + diuron) + (clomazone) & $(171,6+608,4)+(750)$ \\
T8- testemunha capinada & - \\
T9- testemunha sem capina & - \\
\hline
\end{tabular}

Nos experimentos de seletividade, a fitotoxicidade na cultura foi avaliada aos 15, 30, 45, 60, 75 e 100 dias após aplicação (DAA), em escala de 0-10, sendo 0 para toxicidade nula e 10 para morte total das plantas da cana-de-açúcar. Em ambos os experimentos de controle, também aos 15, 30, $45,60,75$ e 100 DAA dos tratamentos, avaliaram-se por meio de escala visual de 0$100 \%$ de controle das plantas daninhas (em que $0 \%$ corresponde a nenhum controle e $100 \%$ controle total das plantas daninhas), conforme recomendações da Sociedade Brasileira da Ciência das Plantas Daninhas (1995). Aos 150 DAA foi determinada ainda a biomassa seca da parte aérea da cultura nos experimentos de controle. Para tanto, foram coletadas aleatoriamente a parte aérea de 20 plantas em cada parcela. Em seguida, os materiais coletados foram levados à estufa de ventilação forçada a $72^{\circ} \mathrm{C}$, por 72 horas, para realização de pesagem.
Os dados foram submetidos a análise de variância. As médias foram comparadas utilizando o teste de agrupamento de ScottKnott, a 5\% de probabilidade (SAEG, 1997).

\section{Resultados e discussão}

As principais plantas daninhas avaliadas nos experimentos foram: picão-preto (Bidens pilosa), capim-colchão (Digitaria sanguinales), capim-marmelada (Brachiaria plantaginea), corda-de-viola (Ipomoea grandifolia), trapoeraba (Commelina benghalensis), guanxuma (Sida rhombifolia), capim colonião (Panicum maximum) e capim carrapicho (Cenchrus echinatus). As densidades de plantas daninhas encontradas nas áreas de Nova Londrina e Marilena, PR, foram de, respectivamente, 18 e 23 plantas por $\mathrm{m}^{2}$.

De acordo com as Tabelas 3 e 4, nos experimentos conduzidos em ambas as áreas experimentais, a maioria dos tratamentos 
Tabela 3. Notas de fitotoxicidade na cultura da cana-de-açúcar em função dos tratamentos experimentais. Nova Londrina/PR, 2006.

\begin{tabular}{|c|c|c|c|c|c|c|c|c|c|c|c|c|}
\hline \multirow{2}{*}{ Tratamentos $^{\underline{1} /}$} & \multicolumn{12}{|c|}{ Notas de Fitotoxicidade (\%) } \\
\hline & \multicolumn{2}{|c|}{$15 \mathrm{DAA}$} & \multicolumn{2}{|c|}{30 DAA } & \multicolumn{2}{|c|}{45 DAA } & \multicolumn{2}{|c|}{60 DAA } & \multicolumn{2}{|c|}{75 DAA } & \multicolumn{2}{|c|}{$100 \mathrm{DAA}$} \\
\hline T1 & 1,0 & $\mathrm{~b}$ & 0,6 & $\mathrm{~b}$ & 0,3 & $\mathrm{~b}$ & 1,6 & $\mathrm{c}$ & 1,0 & $\mathrm{a}$ & 1,0 & $\mathrm{a}$ \\
\hline $\mathrm{T} 2$ & 2,3 & $\mathrm{a}$ & 3,0 & $\mathrm{a}$ & 2,6 & $\mathrm{a}$ & 2,3 & $\mathrm{~b}$ & 1,6 & $\mathrm{a}$ & 1,0 & a \\
\hline T3 & 1,3 & $\mathrm{~b}$ & 1,3 & $\mathrm{~b}$ & 0,3 & $\mathrm{~b}$ & 1,0 & $\mathrm{c}$ & 1,0 & $\mathrm{a}$ & 0,3 & $\mathrm{a}$ \\
\hline $\mathrm{T} 4$ & 0,6 & $\mathrm{~b}$ & 0,6 & $\mathrm{~b}$ & 0,6 & $\mathrm{~b}$ & 1,3 & $\mathrm{c}$ & 0,3 & $\mathrm{~b}$ & 1,0 & $\mathrm{a}$ \\
\hline T5 & 0,6 & $\mathrm{~b}$ & 3,0 & $\mathrm{a}$ & 2,6 & $\mathrm{a}$ & 1,0 & $\mathrm{c}$ & 1,3 & $\mathrm{a}$ & 0,6 & $\mathrm{a}$ \\
\hline T6 & 2,3 & a & 2,6 & a & 12,4 & $\mathrm{a}$ & 2,1 & $\mathrm{~b}$ & 2,0 & $\mathrm{a}$ & 0,6 & $\mathrm{a}$ \\
\hline $\mathrm{T} 7$ & 2,6 & $\mathrm{a}$ & 3,6 & $\mathrm{a}$ & 2,6 & $\mathrm{a}$ & 3,6 & $\mathrm{a}$ & 2,6 & $\mathrm{a}$ & 1,0 & $\mathrm{a}$ \\
\hline T8 & 0,0 & $\mathrm{~b}$ & 0,0 & $\mathrm{~b}$ & 0,0 & $\mathrm{~b}$ & 0,0 & $\mathrm{~d}$ & 0,0 & $\mathrm{~b}$ & 0,0 & $\mathrm{a}$ \\
\hline T9 & 0,0 & $\mathrm{~b}$ & 0,0 & $\mathrm{~b}$ & 0,0 & $\mathrm{~b}$ & 0,0 & $\mathrm{~d}$ & 0,0 & $\mathrm{~b}$ & 0,0 & $\mathrm{a}$ \\
\hline C.V. (\%) & 51 &, 1 & 64 & & & & &, 5 & & 3 & 79 & 7 \\
\hline
\end{tabular}

*As médias seguidas de uma mesma letra minúscula na coluna não diferem entre si pelo teste de agrupamento de Scott-Knott, a $5 \%$ de probabilidade.

${ }^{1 /} \mathrm{T} 1$ (tebuthiuron) + (hexazinone + diuron); T2 (clomazone + ametrina) + (clomazone); T3 (clomazone + ametrina); T4 (trifloxysulfuron sodium + ametrina); T5 (trifloxysulfuron sodium + ametrina) + (hexazinone + diuron); T6 (clomazone + ametrina) + (hexazinone + diuron); T7 (hexazinone + diuron $)+($ clomazone $)$; T8 testemunha capinada; T9 testemunha sem capina.

Tabela 4. Notas de fitotoxicidade na cultura da cana-de-açúcar em função dos tratamentos experimentais. Marilena/PR, 2006.

\begin{tabular}{cccccccc}
\hline \multirow{2}{*}{ Tratamentos $^{\mathbf{1}}{ }^{\prime}$} & $15 \mathrm{DAA}$ & $30 \mathrm{DAA}$ & $45 \mathrm{DAA}$ & $60 \mathrm{DAA}$ & $75 \mathrm{DAA}$ & $100 \mathrm{DAA}$ \\
\cline { 2 - 9 } & $0,3 \mathrm{a}$ & $1,6 \mathrm{~b}$ & $2,0 \mathrm{~b}$ & $2,3 \mathrm{a}$ & $1,6 \mathrm{a}$ & $0,6 \mathrm{a}$ \\
T1 & $0,3 \mathrm{a}$ & $1,3 \mathrm{~b}$ & $2,6 \mathrm{~b}$ & $1,6 \mathrm{~b}$ & $1,3 \mathrm{a}$ & $0,5 \mathrm{a}$ \\
T2 & $0,6 \mathrm{a}$ & $2,3 \mathrm{a}$ & $3,6 \mathrm{a}$ & $2,3 \mathrm{a}$ & $1,6 \mathrm{a}$ & $0,3 \mathrm{a}$ \\
T3 & $0,9 \mathrm{a}$ & $2,6 \mathrm{a}$ & $3,0 \mathrm{a}$ & $1,6 \mathrm{~b}$ & $1,3 \mathrm{a}$ & $0,6 \mathrm{a}$ \\
T4 & $0,3 \mathrm{a}$ & $3,3 \mathrm{a}$ & $3,3 \mathrm{a}$ & $2,6 \mathrm{a}$ & $1,6 \mathrm{a}$ & $0,6 \mathrm{a}$ \\
T5 & $1,0 \mathrm{a}$ & $3,0 \mathrm{a}$ & $3,6 \mathrm{a}$ & $2,3 \mathrm{a}$ & $1,7 \mathrm{a}$ & $0,6 \mathrm{a}$ \\
T6 & $0,6 \mathrm{a}$ & $3,6 \mathrm{a}$ & $2,3 \mathrm{~b}$ & $1,3 \mathrm{~b}$ & $1,3 \mathrm{a}$ & $0,6 \mathrm{a}$ \\
T7 & $0,0 \mathrm{a}$ & $0,0 \mathrm{~b}$ & $0,0 \mathrm{c}$ & $0,0 \mathrm{c}$ & $0,0 \mathrm{~b}$ & $0,0 \mathrm{a}$ \\
T8 & $0,0 \mathrm{a}$ & $0,0 \mathrm{~b}$ & $0,0 \mathrm{c}$ & $0,0 \mathrm{c}$ & $0,0 \mathrm{~b}$ & $0,0 \mathrm{a}$ \\
T9 & 21,1 & 30,4 & 26,6 & 27,3 & 23,3 & 22,6 \\
\hline C.V. $(\%)$ & & &
\end{tabular}

*As médias seguidas de uma mesma letra minúscula na coluna não diferem entre si pelo teste de agrupamento de Scott-Knott, a $5 \%$ de probabilidade.

${ }^{1 /} \mathrm{T} 1$ (tebuthiuron) + (hexazinone + diuron); T2 (clomazone + ametrina) + (clomazone); T3 (clomazone + ametrina); T4 (trifloxysulfuron sodium + ametrina); T5 (trifloxysulfuron sodium + ametrina) + (hexazinone + diuron); T6 (clomazone + ametrina) + (hexazinone + diuron); T7 (hexazinone + diuron $)+($ clomazone $)$; T8 testemunha capinada; T9 testemunha sem capina.

químicos proporcionaram sintomas de moderada nas plantas, visto que nenhuma das fitotoxicidade nas plantas no início do notas de fitotoxicidade foi superior a 3,6 em desenvolvimento da cultura, como cloroses, todos os tratamentos químicos. Posteriormente, necroses e pequenas falhas visuais de brotação. as plantas iniciaram o processo de recuperação, Contudo, as injúrias mostraram-se de leve a no qual esses sintomas foram desaparecendo 
progressivamente (Tabelas 3 e 4). Blanco et al. (1980) descreveram esses sintomas como amarelecimento do limbo foliar, seguido pela requeima das folhas, começando pelo ápice e pelas laterais e, estendendo-se para a nervura central, ocorrendo, em alguns casos, secamento total das folhas. Em Nova Londrina (Tabela 3), evidenciou-se que de modo geral, as aplicações de T2 (clomazone + ametrina) + (clomazone), T5 (trifloxysulfuron sodium + ametrina) + (hexazinone + diuron), T6 (clomazone + ametrina) + (hexazinone + diuron) e $\mathrm{T} 7$ (hexazinone + diuron) + (clomazone) proporcionaram os sintomas mais elevados de toxicidade às plantas até 75 DAA. No entanto, não houve diferenças significativas entre os tratamentos para a variável fitotoxicidade aos 100 DAA (Tabela 3). Este resultado deve-se provavelmente ao fato de que os produtos foram diminuindo o efeito residual e as plantas puderam se recuperar da fitotoxicidade que os herbicidas provocaram na cultura. Cruz \& Gurgell (1983) relatam que alguns herbicidas inibidores de fotossíntese (FS II), como o (hexazinone + diuron) tornam-se mais fitóxicos para a cana-de-açúcar quando usados em associação com outros herbicidas inibidores de pigmentos (carotenos), como clomazone.

De acordo com a Tabela 3, os sintomas de fitotoxicidade na cultura foram menores nas parcelas em que foram aplicados $\mathrm{T} 1$ (tebuthiuron + hexazinone+diuron), $\mathrm{T} 3$ (clomazone + ametrina) e T4 (trifloxysulfuron sodium + ametrina). Dados semelhantes foram obtidos por Azania (2001), com o uso de imazapic, tebuthiuron e (trifloxysulfuron sodium + ametrina) no cultivar RB 835089. O autor observou leve intoxicação na fase inicial do desenvolvimento e total recuperação da cultura da cana-de-açúcar aos 100 DAA, sem prejuízo para produtividade e qualidade da matéria-prima.

Os dados de seletividade obtidos em Marilena/PR, aos 15, 30, 45, 60, 75 e 100 DAA são apresentados na Tabela 4 . Com exceção de
$\mathrm{T} 1$ (tebuthiuron) + (hexazinone + diuron) e $\mathrm{T} 2$ (clomazone + ametrina $)+$ (clomazone), os demais tratamentos químicos causaram sintomas de fitotoxicidade à cultura aos 30 DAA. No entanto, a partir dos 75 DAA não houve mais diferenças significativas nos sintomas de fitotoxicidade dentre os tratamentos químicos estudados (Tabela 4).

Segundo Christoffoleti \& LópezOvejero (2005), herbicidas de alta solubilidade, como tebuthiuron $\left(2.500 \mathrm{ppm}, 25{ }^{\circ} \mathrm{C}\right)$, metribuzin (1.100 ppm, $\left.25^{\circ} \mathrm{C}\right)$ e clomazone (1.100 ppm, $25^{\circ} \mathrm{C}$ ), quando utilizados em períodos de elevada precipitação pluviométrica, podem lixiviar em poucos centímetros na camada superficial. Tal aspecto pode aumentar o potencial de fitotoxicidade dos herbicidas na cultura, por reduzir a seletividade por posicionamento no solo, principalmente em solos arenosos. De acordo com os dados da Estação Meteorológica da COPAGRA (comunicação pessoal), só ocorreu elevada precipitação pluviométrica no mês de Setembro em Marilena (total de $140 \mathrm{~mm}$ ), próximo aos 100 DAA. No entanto, se maior quantidade de chuva tivesse ocorrido em meses anteriores, esse fator poderia ter contribuído para aumentar o contato dos herbicidas com as raízes da cana-de-açúcar e, conseqüentemente, na maior absorção destes produtos que poderiam promover sintomas de intoxicação mais severos.

Aos 100 DAA, praticamente todos os sintomas de fitotoxicidade estavam desaparecendo progressivamente, não apresentando diferenças significativas entre os tratamentos químicos e as testemunhas sem aplicação de herbicidas (Tabela 4). Provavelmente neste período a maioria das moléculas dos herbicidas havia se degradado no solo ou nas plantas. No experimento de controle de plantas daninhas conduzido em Nova Londrina, as primeiras avaliações $(15,30$ e 45 DAA) indicaram que os tratamentos químicos não apresentaram diferenças 
significativas (Tabela 5). Esses resultados podem ser devido à estiagem, pois sem condição de umidade no solo poucas plantas daninhas emergiram nessa fase do experimento. Segundo dados da COPAGRA, as precipitações pluviométricas mensais totalizaram 36, 21 e $63 \mathrm{~mm}$, respectivamente, para Junho, Julho e Agosto, sendo que na data em que foi realizada a última avaliação de fitotoxicidade (4 de Setembro, 100 DAA) 52 mm (COPAGRA, comunicação pessoal).Os dados da Tabela 5 indicam que T1 (tebuthiuron) + (hexazinone + diuron), $\mathrm{T} 2$ (clomazone + ametrina $)+($ clomazone $)$, T5 (trifloxysulfuron sodium + ametrina) + (hexazinone + diuron) e T7 (hexazinone + diuron) + (clomazone) se destacaram em relação aos demais tratamentos químicos aos 60 DAA. No entanto, apenas T1 (tebuthiuron) + (hexazinone + diuron) e T7 (hexazinone + diuron $)+($ clomazone) mantiveram os melhores resultados de controle das plantas daninhas até aos 100 DAA, visto que as demais misturas foram diminuindo sua eficiência de controle a partir dos 60 DAA (Tabela 5). Segundo Rodrigues \& Almeida (2005) a persistência da mistura (clomazone + ametrina) + (clomazone) varia de 60 à 90 dias, (trifloxysulfuron sodium + ametrina) em torno de 60 dias e para (hexazinone + diuron) é de 90 dias, sendo que estes valores estão coerentes com os obtidos nesse estudo.

Tabela 5. Porcentagem de controle das plantas daninhas ao longo do tempo e biomassa seca da parte aérea da cana-de-açúcar aos 150 DAA, em função dos tratamentos experimentais. Nova Londrina/PR, 2006.

\begin{tabular}{|c|c|c|c|c|c|c|c|}
\hline \multirow[t]{2}{*}{ Trat. ${ }^{1 /}$} & \multicolumn{6}{|c|}{ Controle (\%) } & \multirow{2}{*}{$\begin{array}{c}\begin{array}{c}\text { Biomassa } \\
\text { seca }(\mathbf{g})\end{array} \\
150 \text { DAA } \\
\end{array}$} \\
\hline & $15 \mathrm{DAA}$ & $30 \mathrm{DAA}$ & $45 \mathrm{DAA}$ & 60 DAA & $75 \mathrm{DAA}$ & 100 DAA & \\
\hline $\mathrm{T} 1$ & $100 \mathrm{a}$ & $100 \mathrm{a}$ & $100 \mathrm{a}$ & $100,0 \mathrm{a}$ & $98,3 \mathrm{a}$ & $100,0 \mathrm{a}$ & 1975,8 a \\
\hline $\mathrm{T} 2$ & $100 \mathrm{a}$ & $100 \mathrm{a}$ & $100 \mathrm{a}$ & $100,0 \mathrm{a}$ & 96,6 a & $90,0 \mathrm{~b}$ & $1995,0 \quad \mathrm{a}$ \\
\hline T3 & $100 \mathrm{a}$ & $100 \mathrm{a}$ & $100 \mathrm{a}$ & $95,0 \quad b$ & 86,6 b & $86,6 \mathrm{~b}$ & 1774,9 a \\
\hline $\mathrm{T} 4$ & $100 \mathrm{a}$ & $100 \mathrm{a}$ & $100 \mathrm{a}$ & $93,3 \mathrm{~b}$ & $91,6 \mathrm{~b}$ & $86,6 \mathrm{~b}$ & $1841,8 \mathrm{a}$ \\
\hline T5 & $100 \mathrm{a}$ & $100 \mathrm{a}$ & $100 \mathrm{a}$ & $100,0 \mathrm{a}$ & $92,3 \mathrm{~b}$ & $86,6 \mathrm{~b}$ & $2022,0 \quad \mathrm{a}$ \\
\hline T6 & $100 \mathrm{a}$ & $100 \mathrm{a}$ & $100 \mathrm{a}$ & $95,0 \quad b$ & $90,0 \mathrm{~b}$ & $86,6 \mathrm{~b}$ & 2067,8 a \\
\hline $\mathrm{T} 7$ & $100 \mathrm{a}$ & $100 \mathrm{a}$ & $100 \mathrm{a}$ & $100,0 \mathrm{a}$ & 96,6 a & 95,0 a & 2056,4 a \\
\hline $\mathrm{T} 8$ & $100 \mathrm{a}$ & $100 \mathrm{a}$ & $100 \mathrm{a}$ & 100,0 a & $100,0 \mathrm{a}$ & $100,0 \mathrm{a}$ & 1999,8 a \\
\hline T9 & $0,0 \mathrm{~b}$ & $0,0 \mathrm{~b}$ & $0,0 \mathrm{~b}$ & $0,0 \mathrm{c}$ & $0,0 \mathrm{~b}$ & $0,0 \mathrm{c}$ & $982,1 \quad b$ \\
\hline C.V. & $1,9 \%$ & $3,0 \%$ & $2,8 \%$ & $3,9 \%$ & $6,4 \%$ & $5,7 \%$ & $13,5 \%$ \\
\hline
\end{tabular}

*As médias seguidas de uma mesma letra minúscula na coluna não diferem entre si pelo teste de agrupamento de Scott-Knott, a $5 \%$ de probabilidade.

${ }^{1 /} \mathrm{T} 1$ (tebuthiuron) + (hexazinone + diuron); T2 (clomazone + ametrina) + (clomazone); T3 (clomazone + ametrina); T4 (trifloxysulfuron sodium + ametrina); T5 (trifloxysulfuron sodium + ametrina) + (hexazinone + diuron); T6 $($ clomazone + ametrina $)+($ hexazinone + diuron $)$, T7 (hexazinone + diuron $)+($ clomazone $)$; T8 testemunha capinada; T9 testemunha sem capina.

No experimento conduzido em nesses resultados, evidencia-se que esses Marilena, PR, as primeiras avaliações de tratamentos proporcionaram residuais controle de plantas daninhas realizadas aos 15, suficientes para controlar as plantas daninhas 30 e 45 DAA, não apresentaram diferenças que germinaram nesse período. Posteriormente, significativas entre os tratamentos, exceto na segundo dados da Tabela 6, os herbicidas T5 testemunha sem capina (Tabela 6). Com base (trifloxysulfuron sodium + ametrina) + 
(hexazinone + diuron) e T6 (clomazone + ametrina) + (hexazinone + diuron) se destacaram em relação aos demais obtendo controle total das plantas daninhas até aos 100 DAA, não diferindo da testemunha capinada (Tabela 6). Na literatura os dados de persistência destas misturas são superiores a 90 dias (Rodrigues \& Almeida, 2005).

Tabela 6. Porcentagem de controle das plantas daninhas ao longo do tempo e biomassa seca da parte aérea da cana-de-açúcar aos 150 DAA, em função dos tratamentos experimentais. Marilena/PR, 2006.

\begin{tabular}{|c|c|c|c|c|c|c|c|}
\hline Trat. ${ }^{1 /}$ & & & Cont & le $(\%)$ & & & $\begin{array}{c}\text { Biomassa } \\
\text { seca }(g)\end{array}$ \\
\hline & 15 DAA & 30 DAA & 45 DAA & 60 DAA & 75 DAA & 100 DAA & 150 DAA \\
\hline T1 & $100,0 \mathrm{a}$ & $100,0 \mathrm{a}$ & $100,0 \mathrm{a}$ & 93,3 a & 86,6 a & $90,0 \mathrm{~b}$ & $1785,8 \mathrm{a}$ \\
\hline $\mathrm{T} 2$ & 100,0 a & 93,3 a & 100,0 a & $86,6 \mathrm{~b}$ & 85,0 a & $80,8 \mathrm{c}$ & $1995,0 \mathrm{a}$ \\
\hline T3 & $100,0 \mathrm{a}$ & $100,0 \mathrm{a}$ & 93,3 a & 93,3 a & 86,6 a & $85,0 \mathrm{c}$ & $1774,0 \mathrm{a}$ \\
\hline $\mathrm{T}$ & $100,0 \mathrm{a}$ & $100,0 \mathrm{a}$ & $100,0 \mathrm{a}$ & 96,6 a & 85,0 a & $81,6 \mathrm{c}$ & $1849,8 \mathrm{a}$ \\
\hline T5 & $100,0 \mathrm{a}$ & $100,0 \mathrm{a}$ & $100,0 \mathrm{a}$ & $100,0 \mathrm{a}$ & 93,3 a & $100,0 \mathrm{a}$ & $2022,0 \mathrm{a}$ \\
\hline T6 & $100,0 \mathrm{a}$ & 100,0 a & $100,0 \mathrm{a}$ & 93,3 a & 91,6 a & $100,0 \mathrm{a}$ & $2067,8 \mathrm{a}$ \\
\hline $\mathrm{T} 7$ & 93,0 a & $100,0 \mathrm{a}$ & 93,3 a & $86,6 \mathrm{~b}$ & 93,3 a & $91,6 \mathrm{~b}$ & $2056,4 \mathrm{a}$ \\
\hline $\mathrm{T} 8$ & $100,0 \mathrm{a}$ & $100,0 \mathrm{a}$ & $100,0 \mathrm{a}$ & $100,0 \mathrm{a}$ & $100,0 \mathrm{a}$ & $100,0 \mathrm{a}$ & $1991,3 \mathrm{a}$ \\
\hline T9 & $0,0 \mathrm{~b}$ & $0,0 \mathrm{~b}$ & $0,0 \mathrm{~b}$ & $0,0 \mathrm{c}$ & $0,0 \mathrm{~b}$ & $0,0 \mathrm{~d}$ & $847,1 \mathrm{~b}$ \\
\hline C.V. & $5,5 \%$ & $5,6 \%$ & $8,1 \%$ & $5,8 \%$ & $8,4 \%$ & $5,6 \%$ & $15,0 \%$ \\
\hline
\end{tabular}

*As médias seguidas de uma mesma letra minúscula na coluna não diferem entre si pelo teste de agrupamento de Scott-Knott, a 5\% de probabilidade.

${ }^{1 /} \mathrm{T} 1$ (tebuthiuron) + (hexazinone + diuron); T2 (clomazone + ametrina) + (clomazone); T3 (clomazone + ametrina); T4 (trifloxysulfuron sodium + ametrina); T5 (trifloxysulfuron sodium + ametrina) + (hexazinone + diuron); T6 (clomazone + ametrina) + (hexazinone + diuron); T7 (hexazinone + diuron) + (clomazone); T8 testemunha capinada; T9 testemunha sem capina.

Dentre os vários fatores que podem influenciar a eficiência dos herbicidas residuais, destaca-se a presença da palha e a capacidade do herbicida atingir o solo, que pode estar diretamente relacionada à ocorrência de precipitações após a aplicação do produto (Medeiros, 2001). Em Marilena, ocorreu uma precipitação de $35 \mathrm{~mm} 2$ DAA dos tratamentos (COPAGRA, comunicação pessoal), o que pode ter promovido pequena lixiviação das moléculas do herbicida na camada superficial do solo, favorecendo o residual que foi constatado até aos 100 DAA no T5 (trifloxysulfuron sodium + ametrina) + (hexazinone + diuron) e T6 (clomazone + ametrina) + (hexazinone + diuron). De acordo com Oliveira (2001), pequena lixiviação é desejável, torna o herbicida mais eficiente, movendo-o da superfície do solo para onde estão concentradas as sementes de plantas daninhas, uma vez que, a maioria das sementes daninhas se encontra nos $5 \mathrm{~cm}$ superficiais do solo. Os dados da Tabela 6 indicam que os demais tratamentos químicos mantiveram controle eficiente até aos 75 DAA, semelhantes à testemunha capinada. Verificou-se ainda que, independente das datas das avaliações, todos os tratamentos químicos proporcionaram controle acima de $80 \%$ (Tabela 6).

Ao analisar os experimentos conduzidos em ambas as áreas experimentais, observa-se que apesar dos tratamentos apresentarem diferenças significativas em algumas avaliações de fitotoxicidade na cultura e controle de plantas daninhas (Tabelas 3 a 6), verifica-se que os tratamentos não 
apresentaram diferenças significativas para a biomassa seca da parte aérea das plantas obtida aos 150 DAA (Tabelas 5 e 6). Portanto, evidencia-se que os tratamentos químicos não influenciaram significativamente $O$ desenvolvimento da cultura aos 150 DAA. Esses resultados estão de acordo com os de Negrisoli (2003) e Negrisoli et al. (2004), que também não observaram diferenças significativas de rendimento para as diversas associações avaliadas.

Ao comparar os valores de produção de biomassa (Tabelas 5 e 6), verificou-se que, em relação à média produzida pelas plantas que receberam os tratamentos químicos, a presença das plantas daninhas nas parcelas da testemunha sem herbicida reduziu cerca de $49,9 \%$ e 56,2\%, respectivamente, nas áreas de Nova Londrina e Marilena.

\section{Conclusões}

Nas condições em que os experimentos foram conduzidos, considerou-se que todas as associações de herbicidas avaliadas foram viáveis para serem aplicadas na cultura da cana-de-açúcar. Para tanto, utilizou-se como parâmetros os efeitos que as associações proporcionaram na fitotoxicidade da cultura, no controle de plantas daninhas e na biomassa da parte aérea aos 150 DAA.

\section{Referências}

AZANIA, C.A.M. Seletividade de imazapic às soqueiras de cana-de-açúcar(Saccharum spp.). Planta Daninha, v.19, p.345-350, 2001.

BARELA, J.F.; CHRISTOFFOLETI, P. J. Seletividade de herbicidas aplicados em préemergência da cultura da cana-de-açúcar (RB 867515) tratada com nematicidas. Planta Daninha, v.24, p.83-90, 2006.

BLANCO, H.G.; BARBOSA, J.C.; OLIVEIRA, D. A. Fitotoxicidade em cana-de- açúcar causada pela interação de inseticida e herbicida residual. O Biológico, v.46, p.235240, 1980.

BLANCO, H.G.; BARBOSA, J.C.; OLIVEIRA, D. A. Competição de uma comunidade natural de mato em cultura de cana-de-açúcar (Saccharum sp.), de ano e meio. O Biológico, v.48, p.30-31, 1982.

CHRISTOFFOLETI, P. J.; LÓPES-OVEJERO, R. F. Dinâmica dos herbicidas aplicados ao solo na cultura da cana-de-açúcar. Piracicaba: BASF, 2005. 49 p.

CONAB (Companhia Nacional de Abastecimento). Cana-de-açúcar, 2007. Disponível em: $<$ http://www.conab.gov.br/conabweb/downloa $\mathrm{d} /$ sureg/PR/Cana\%20de\%20acucar\%20Maio\% 202008.pdf>. Acesso em: 06 out. 2008.

CONSTANTIN, J.; CONTIERO, R. L.; ZAGATTO, A. Eficiência e fitotoxicidade do herbicida Isouron, comparado com herbicidas tradicionais, na cultura da cana-de-açúcar. Unimar, v.18, p.477-486, 2002.

CRUZ, L. S. P.; GURGELL, M. N. A. Efeito de hexazinone e diuron, e suas misturas, no controle de capim-colchão (Digitaria sanguinalis) em cana-de-açúcar (Saccharum spp.). Planta Daninha, v.1, p.15-20, 1983.

IEA (Instituto de Economia Agrícola). Defensivos Agrícolas: rumo a uma retomada sustentável, 2008. Disponível em: $<$ http://www.iea.sp.gov.br/out/ver Texto.php?codTexto=9200>. Acesso em: 06 out. 2008 .

LORENZI, H. Plantas daninhas na cultura da cana-de-açúcar. In: ENCONTRO TÉCNICO GOAL， CANA-DE-AÇÚCAR， 4., 1995, Recife. Anais... Recife: Dow AgroSciences, 1995. p.10-20. 
MEDEIROS, D. Efeitos da palha de cana-deaçúcar (Saccharum spp.) sobre o manejo de plantas daninhas e dinâmica do banco de sementes. Piracicaba: Escola Superior de Agricultura Luiz de Queiroz, 2001. 126p. Dissertação (Mestrado em Fitotecnia) - Escola Superior de Agricultura Luiz de Queiroz, 2001.

NEGRISOLI, E. Seletividade de herbicidas aplicados em pré-emergência e associados à nematicidas, à cultura da cana-de-açúcar cultivar RB-855113. Botucatu: Universidade Estadual Paulista Julio de Mesquita Filho, 2003. 48 f. Dissertação (Mestrado em Agronomia) - Universidade Estadual Paulista Julio de Mesquita Filho, Botucatu, 2003.

NEGRISOLI, E.; VELINI, E. D.; TOFOLI, G. R.; CAVENAGHI, A. L.; MARTINS, D.; MORELLI, J. L.; COSTA, A. G. F. Seletividade de herbicidas aplicados em préemergência na cultura de cana-de-açúcar tratada com nematicidas. Planta Daninha, v.22, p.567-575, 2004.

OLIVEIRA, M.F. Comportamento de herbicidas no ambiente. In: OLIVEIRA JR., R. S.; CONSTANTIN, J. Plantas daninhas e seu manejo. Guaíba: Agropecuária, 2001. p. 315362.

RODRIGUES, B.N.; ALMEIDA, F. L. S. Guia de herbicidas, 5.ed. Londrina: IAPAR, 2005. $592 p$.

SAEG - Sistema para Análises Estatísticas: versão 7.0. Viçosa: Fundação Arthur Bernardes, 1997.

SOCIEDADE BRASILEIRA DA CIÊNCIA DAS PLANTAS DANINHAS. Procedimentos para instalação, avaliação e análise de experimentos com herbicidas. Londrina: SBCPD, 1995, p.42. 